\title{
Impact of Pharmacist Obesity Diagnosis Education on Patient Self-Rated Health and Health Behavior: A Pilot Study
}

\author{
Vincent Ekenga ${ }^{1^{*}}$ and Monica Skomo ${ }^{2}$ \\ ${ }^{1}$ College of Pharmacy, Xavier University of Louisiana, New Orleans, LA 70125, USA \\ ${ }^{2}$ School of Pharmacy, Duquesne University - Center for Pharmacy Care, Pittsburgh, PA 15219, USA
}

Correspondence to:

Vincent Ekenga, Pharm D, CDE

Xavier University of Louisiana

College of Pharmacy

1 Drexel Drive

New Orleans LA 70125, USA

Tel: (314) 571-8201

E-mail: vekenga@xula.edu

Received: June 19, 2017

Accepted: August 14, 2017

Published: August 17, 2017

Citation: Ekenga V, Skomo M. 2017. Impact of Pharmacist Obesity Diagnosis Education on Patient Self-Rated Health and Health Behavior: A Pilot Study. J Obes Chronic Dis 1(2): 39-42.

Copyright: (C) 2017 Ekenga and Skomo. This is an Open Access article distributed under the terms of the Creative Commons Attribution 4.0 International License (CC-BY) (http:// creativecommons.org/licenses/by/4.0/) which permits commercial use, including reproduction, adaptation, and distribution of the article provided the original author and source are credited.

Published by United Scientific Group

\section{Abstract}

Purpose: To determine the impact of pharmacist-provided obesity diagnosis education, after a health assessment, on patient self-rated health and health behaviors.

Study Design: Unblinded, randomized cross-sectional prospective study with a pre-intervention and post-intervention survey.

Methods: Insured employee participants, with a BMI greater than $25 \mathrm{~kg} / \mathrm{m}^{2}$, completed a survey assessing their self-rated health and health behaviors utilizing the "Starting the Conversation" and "Rapid Assessment of Physical Activity" questionnaires. Participants were randomized, via computer software, to either a standard counseling group (control) or an enhanced counseling group. In the standard counseling group clinical pharmacists addressed three areas: overweight or obesity assessment based on BMI, recommended weekly physical activity, and a healthy eating strategy. The enhanced counseling addressed all three standard counseling areas and included obesity diagnosis education, detailing obesity as a disease and clinical diagnosis.

Results: Both the standard counseling group and the enhanced counseling group improved eating habits post intervention. Pharmacist-delivered obesity diagnosis education did not have a statically significant impact patient self-rated health, physical activity, or dietary habits ( $\mathrm{p}=0.564,0.416,0.102$ respectively).

Conclusion and Clinical Relevance: Self-rated health is a predictor of morbidity and mortality. Identifying brief clinical interventions that can positively impact self-rated health can be used to improve overall health throughout primary care settings. A larger study is necessary to fully assess the positive impact of pharmacist-delivered obesity education and health assessments, together and individually.

\section{Keywords}

Obesity, Self-rated health, Starting the conversation, Rapid assessment of physical activity, Pharmacist, Education

\section{Introduction}

Obesity, a growing health epidemic that currently affects more than onethird of American adults, is an important risk factor for many chronic conditions including hypertension, coronary artery disease and osteoarthritis [1]. Overweight and obesity are metabolic conditions. They can be coded within International Classification of Disease, Tenth Revision (ICD-10), and Medicare will provide reimbursement to healthcare providers for services when weight becomes higher 
than what is considered healthy [2]. Screening for obesity status is generally completed using body mass index (BMI), which is a function of a person's height and weight. A high BMI generally correlates to high body fatness. Persons are considered to be obese if their BMI is $30 \mathrm{~kg} / \mathrm{m}^{2}$ or greater and to be overweight if their BMI is 25 to $29.9 \mathrm{~kg} / \mathrm{m}^{2}$ [3].

In an effort to decrease obesity rates and improve health, the U.S. Department of Health and Human Services (HHS) has issued guidelines on recommended physical activity. Similar to obese adults, inactive adults have a higher risk for early death, heart disease, diabetes and some cancers. The 2008 Physical Activity Guidelines for Americans recommend 150 minutes of moderate-intensity aerobic activity or 75 minutes of vigorousintensity aerobic activity combined with two or more days of muscle strengthening activities per week [4]. Currently, only about one in five adults meet this recommendation [5].

To compound this problem, studies have indicated that obesity is under-diagnosed and under-addressed by healthcare professionals. According to the American Academy of Family Physicians (AAFP), clinical practice guidelines encourage physicians to identify and counsel obese patients. However, many practitioners do not address the issue even with patients who meet the diagnostic criteria [6]. One study observed that less than one-third of patients meeting BMI criteria for obesity received a documented diagnosis for obesity [7], indicating that obesity is not being addressed in a manner similar to other health conditions. An increase in accurate and timely diagnoses for overweight and obese patients could positively impact weight-related health consequences [8].

Simple screening services and lifestyle counseling have the potential to motivate lifestyle modifications and improve condition awareness [9]. Behavioral changes in obese patients, including healthier food selection, caloric restriction, and increased physical activity, have been shown to be effective for long-term weight management and prevention of chronic disease $[10,11]$. Pu et al. found that positive patient behavior changes can occur after a health assessment and feedback. Patients reported an increase in formal diagnosis, an increase in exercise and a decrease in smoking and alcohol consumption [12].

Risk assessment and notification to patients that they meet the criteria for the weight related disease, obesity, has never been evaluated for its efficacy to cause a change in health behavior or self-rated health.

Self-rated health has been shown to be a consistent predictor of morbidity and mortality [13-16]. This pilot study aims to identify a potentially successful strategy to both induce health behavior changes and improve self-rated health; such a strategy of educating patients on their obesity as a health condition could influence patient consultation models, overall patient health and increase the possibility of clinically significant weight loss.

\section{Methods}

This prospective study with a pre-intervention and postintervention survey was conducted over a 6-month period from November 2016 to April 2017, after approval from an Institutional Review Board.

For the purposes of this study, prospective participants were patients presenting to a pharmacist-coordinated ambulatory care clinic in Pittsburgh, Pennsylvania for regular care during the first three months of the study period. The clinic is housed on an academic campus and operates preventative care and disease management programs, with services available to employees and the public. In order to qualify for inclusion, participants had to be 18 years of age or older, a patient of the clinic, have a BMI of $25 \mathrm{~kg} / \mathrm{m}^{2}$ or greater, and not be pregnant, or participating in any medically supervised weight loss program. Study-trained clinical pharmacists recruited patients during regularly scheduled appointments. After providing written informed consent, interested participants completed a survey on a tablet, were randomized via a random number assignment to one of two study groups (standard vs. enhanced), and then completed a health assessment. The survey acquired information on demographics, self-rated health, and health behavior. The health assessment consisted of height, weight, blood pressure, blood glucose, blood cholesterol and body composition analysis via a professional electronic scale. Following the health assessment, participants then received standardized counseling from a pharmacist corresponding to their appropriate study group. Participants repeated the survey again, 60 to 90 days later, with or without a health assessment.

Data were analyzed using SPSS Version 24. Descriptive statistics were recorded and Wilcoxon signed-rank test was used to analyze group means for change in self-rated health and health behavior. The level of significance was set at an alpha level of 0.05 .

\section{Materials}

\section{Self-rated health}

Self-rated health, sometimes referred to as self-assessed health, was measured via a single item. The item asks participants to rate their general health as excellent, very good, good, fair or poor. These answer choices correspond to a 5-point scale (Excellent 1 - Poor 5).

\section{Starting the conversation (STC)}

The "Starting The Conversation" questionnaire was used to assess dietary patterns. It is an eight-item instrument designed for non-dietitians to use in clinical practice [17]. Participants respond to questions indicating the frequency of specific food intake. Answers are scored from zero points to two points, with a higher score (max of 16) indicating a less healthful diet.

\section{Rapid assessment of physical activity (RAPA)}

The "Rapid Assessment of Physical Activity" questionnaire was used to assess the quantity and category of physical activity [18]. It is a nine-item instrument useful in clinical practice. Participants indicate "yes" or "no" to each of the nine questions, which inquire about the frequency and intensity of aerobic, strength, and flexibility activities completed. Those who indicate "yes" to question six, "completing 30 minutes or 
more a day of moderate physical activities, 5 or more days a week", meet or exceed the recommendation made in the 2008 Physical Activity Guidelines for Americans.

These three items, as wells as demographic information, were obtained from a self-administered survey, via an online platform.

\section{Intervention}

The standard counseling addressed three areas: overweight or obesity assessment based on BMI, recommended weekly physical activity based on the United States Health and Human Services 2008 Physical Activity Guidelines, and the United States Department of Agriculture's MyPlate method to develop a healthy eating strategy. The enhanced counseling (intervention group) addressed all three standard counseling areas and included obesity diagnosis education. Enhanced counseling group participants were explained that: (1) obesity is a disease characterized by excess body fat and body weight; (2) Similar to other chronic diseases, such as hypertension and diabetes, obesity can impair bodily function and increase mortality; (3) Diagnosis occurs when a BMI is greater than $30 \mathrm{~kg} / \mathrm{m}^{2}$; and (4) If a patient was obese, they were explained why they meet the criteria necessary for an obesity diagnosis and a diagnosis can be formally made by a diagnosing healthcare provider.

\section{Results}

A total of 11 patients were identified and enrolled in this study between November 2016 and January 2017. Four participants were excluded due to not meeting the BMI requirements and one participant was lost to follow up; their information was not included for data analysis. Baseline characteristics of the study population are shown in Table 1. Participants were mostly middle-aged males with a mean BMI of $39.25 \mathrm{~kg} / \mathrm{m}^{2}$. All participants were white. Two participants were assigned to the enhanced counseling group and four to the standard counseling group.

Table 1: Patient demographic information and group randomization.

\begin{tabular}{|l|l|l|}
\hline Measure & Female & $\mathbf{N}=6$ \\
\hline Gender & Male & 2 \\
\hline Age & Mean & 4 \\
\hline Race & White & 6 \\
\hline BMI & Mean & 39.25 \\
\hline Counseling Group & Standard & 4 \\
\hline
\end{tabular}

Table 2 displays the results from the pre-intervention survey. The self-rated health score (3.5) was the same for both the standard and enhanced counseling groups. Rapid Assessment of Physical Activity (RAPA) scores are also the same for both groups prior to the intervention, with $50 \%$ of each group achieving a RAPA level of 6 or better. Starting The Conversation (STC) dietary scores are similar, as well, between the standard and enhanced counseling groups, 7.5 and 8.0 respectively.

Table 2: Pre and post-intervention survey results.

\begin{tabular}{|c|c|c|c|}
\hline Measure & $\begin{array}{l}\text { Mean Score } \\
\text { (Survey 1) }\end{array}$ & $\begin{array}{l}\text { Mean Score } \\
\text { (Survey 2) }\end{array}$ & $P$-value \\
\hline $\begin{array}{l}\text { Self-Rated } \\
\text { Health } \\
\text { (Excellent 1- } \\
\text { Poor 5) }\end{array}$ & $\begin{array}{l}\text { Standard } 3.5 \\
\text { Enhanced } 3.5\end{array}$ & $\begin{array}{l}\text { Standard } 3.25 \\
\text { Enhanced } 3.5\end{array}$ & .564 \\
\hline $\begin{array}{l}\text { RAPA of } 6 \text { or } \\
\text { greater }\end{array}$ & $\begin{array}{ll}\text { Standard } & 50 \% \\
\text { Enhanced } & 50 \%\end{array}$ & $\begin{array}{l}\text { Standard } 25 \% \\
\text { Enhanced }\end{array}$ & .416 \\
\hline STC & $\begin{array}{l}\text { Standard } 7.5 \\
\text { Enhanced } 8.0\end{array}$ & $\begin{array}{l}\text { Standard } 6.75 \\
\text { Enhanced } \quad 7.5\end{array}$ & .102 \\
\hline
\end{tabular}

After the intervention, self-rated health remained the same for the enhanced group and slightly improved for the standard group, 3.5 and 3.25 respectively. Physical activity decreased for both groups, with only $25 \%$ of the standard group and $0 \%$ of the enhanced counseling group achieving level 6 or better for aerobic activity. Starting The Conversation dietary scores improved to 6.75 for the standard group and to 7.5 for the enhanced group. When comparing the postintervention data of the standard group to the enhanced group, the differences in self-rated health, physical activity (RAPA score) and dietary intake (STC score) were found not to be statistically significant ( $\mathrm{p}=0.564,0.416,0.102$ respectively).

\section{Discussion}

Overall improvement in self-rated health and dietary intake was noted. However, we cannot attribute this improvement to the pharmacist-delivered obesity diagnosis education intervention because, although not statistically significant, the standard group displayed larger numerical improvements in comparison to the enhanced counseling group. Results are consistent with several previous findings that a brief intervention and health assessment can result in positive health behavior changes $[8,11]$.

A decrease in physical activity was observed for both groups of participants. This observation is compatible with previous findings that season, weather, and region can affect physical activity. Several studies attribute colder weather to decreased activity levels [19]. This study took place during fall and winter seasons, and the research site is located in a northeastern city.

Sample size is a limitation to the generalizability of these study results. We recruited participants during a low-volume time-period for a clinic housed on an academic campus. Nevertheless, this study serves as a pilot study to examine the impact of an obesity diagnosis educational intervention. 
No previous studies are available to compare the consistency of results, however, larger sample sizes with additional BMI follow-up assessments are needed to establish the consistent impact of educating patients on obesity as a clinical condition and its impact on self-rated health. Future investigations, with longer time periods for enrollment and follow-up, are warranted.

\section{Conclusion}

Pharmacist-delivered obesity diagnosis education did not significantly impact patient self-rated health or health behavior. Self-rated health is correlated to the occurrence of several chronic diseases. More data is needed to assess whether self-rated health can be influenced by pharmacist-delivered obesity diagnosis education. If obesity diagnosis education is found to influence self-rated-health, then more research will be needed to assess this impact on chronic disease occurrence.

\section{Conflict of Interest}

$\mathrm{VE}$ and MS declare no conflict of interest.

\section{Acknowledgements}

The authors thank Courtney Olesky and Nancy Lee for their assistance throughout the research process. The authors also thank Dr. Gibbs Kanyongo for data analysis assistance, and Dr. Christine Ekenga for manuscript review.

\section{References}

1. Ogden CL, Carroll MD, Kit BK, Flegal KM. 2014. Prevalence of childhood and adult obesity in the United States, 2011-2012. JAMA 311(8): 806-814. https://doi.org/10.1001/jama.2014.732

2. Medicare Preventative Services. Department of Health \& Human Services, USA.

3. Lemay CA, Cashman S, Savageau J, Fletcher K, Kinney R, et al. 2003. Underdiagnosis of obesity at a community health center. $J$ Am Board Fam Pract 16(1): 14-21. https://doi.org/10.3122/jabfm.16.1.14

4. Physical Activity Guidelines Advisory Committee. 2008. Physical activity guidelines advisory committee report, 2008. Department of Health and Human Services, Washington, DC, USA.

5. Centers for Disease Control and Prevention.

6. McKinney L, Skolnik N, Chrusch A. 2013. Diagnosis and management of obesity. American Academy of Family Physicians, KS, USA.
7. Bleich SN, Pickett-Blakely O, Cooper LA. 2011. Physician practice patterns of obesity diagnosis and weight-related counseling. Patient Educ Couns 82(1): 123-129. http://doi.org/10.1016/j.pec.2010.02.018

8. Vasudevan DA, Northrup TF, Mandayam S, Bamidele OO, Stotts AL. 2017. Impact of physician training on diagnosis and counseling of overweight and obese Asian patients. J Racial Ethn Health Disparities 4(3): 322-328. https://doi.org/10.1007/s40615-016-0231-2

9. Cadilhac DA, Kilkenny MF, Johnson R, Wilkinson B, Amatya B, et al. 2015. The know your numbers (KYN) program 2008 to 2010: impact on knowledge and health promotion behavior among participants. Int $J$ Stroke 10(1): 110-116. https://doi.org/10.1111/ijs.12018

10. Carpenter KM, Lovejoy JC, Lange JM, Hapgood JE, Zbikowski SM. 2014. Outcomes and utilization of a low intensity workplace weight loss program. J Obes 2014: 414987. http://doi.org/10.1155/2014/414987

11. Ratner RE, Diabetes Prevention Program Research. 2006. An update on the diabetes prevention program. Endocr Pract 12(Suppl 1): 20-24. https://doi.org/10.4158/EP.12.S1.20

12. Pu J, Chewning BA, Johnson HM, Vanness DJ, Young HN, et al. 2015. Health behavior change after blood pressure feedback. PLoS One 10(10): e0141217. http://doi.org/10.1371/journal.pone.0141217

13. DeSalvo KB, Bloser N, Reynolds K, He J, Muntner P. 2006. Mortality prediction with a single general self-rated health question. A metaanalysis. J Gen Intern Med 21(3): 267-275. http://doi.org/10.1111/ j.1525-1497.2005.00291.x

14. Haddock CK, Poston WSC, Pyle SA, Klesges RC, Vander Weg MW. 2006. The validity of self-rated health as a measure of health status among young military personnel: evidence from a cross-sectional survey. Health Oual Life Outcomes 4: 57. http://doi.org/10.1186/14777525-4-57

15. Latham K, Peek CW. 2013. Self-rated health and morbidity onset among late midlife U.S. adults. J Gerontol B Psychol Sci Soc Sci 68(1): 107-116. http://doi.org/10.1093/geronb/gbs104

16. Meng Q, Xie Z, Zhang T. 2014. A single-item self-rated health measure correlates with objective health status in the elderly: a survey in suburban beijing. Front Public Health 2: 27. http://doi.org/10.3389/ fpubh.2014.00027

17. Paxton AE, Strycker LA, Toobert DJ, Ammerman AS, Glasgow RE. 2011. Starting the conversation performance of a brief dietary assessment and intervention tool for health professionals. Am J Prev Med 40(1): 67-71. http://doi.org/10.1016/j.amepre.2010.10.009

18. Rapid Assessment of Physical Activity (RAPA). 2006. How physically active are you? University of Washington Health Promotion Research Center. Funded in part by the Centers for Disease Control (Reproduced with permission).

19. Tucker P, Gilliland J. 2007. The effect of season and weather on physical activity: a systematic review. Public Health 121(12): 909-922. http://doi. org/10.1016/j.puhe.2007.04.009 